\title{
BASAL GASTRIC SECRETION IN CASES OF PEPTIC ULCER: RELATION OF ACIDITY TO HEALING OF ULCER
}

\author{
By A. L. BLOOMFIELD AND L. R. FRENCH \\ (From the Department of Medicine, Stanford University School of Medicine, San Francisco)
}

(Received for publication June 1, 1938)

In studying gastric secretion it has been customary to promote the flow of juice by some sort of artificial stimulus, whether food or drug, and such a procedure is of obvious importance where the digestive capabilities of the stomach are under consideration. There is, however, another aspect of stomach function which is of value in clinical medicine, namely an assay of the secretions under resting or basal conditions. Here one exposes the spontaneous play of autonomic nerves on the secreting cells as well as possible hormonic effects or "inherent" cellular activity, without the confusing element of external stimuli which promote maximal secretion and tend to wipe out individual differences. It is obvious that the correlations of basal gastric secretion with disease may be quite different from those detected after the powerful stimulus of histamine.

\section{METHODS}

The technique of obtaining basal gastric secretion has been described elsewhere (1). Briefly, the patient is prepared as for a metabolism test; he is at rest in bed, warm, and he has taken no food for at least twelve hours. A small tube is slipped into the stomach with the least possible disturbance and the fasting contents are withdrawn. Continuous aspiration is then kept up over successive ten-minute periods until an approximately constant ten-minute secretory volume is obtained-an indication that a basal level has been reached. The entire test usually occupies from one to two hours. In some subjects there is an obvious stimulation of secretion by passage of the tube; in others there seems to be a temporary inhibition. Results in different patients are conveniently assessed by comparing the tenminute basal output of juice as well as its acidity, or the volume obtained over a longer period may be measured. Table I gives the results in an illustrative case.

When measurements of basal secretion are car- ried out repeatedly on the same person a surprising constancy is observed although the findings vary greatly in different " normal" people (1). In one, both volume of secretion and acidity are low, in another, there may be a continuous abundant flow of highly acid juice, and in a third, there may be a small quantity of very acid secretion or vice versa. In those whose basal secretion is highly acid there is little further increase after a full dose of histamine-such a stomach is already working at nearly top speed (1).

TABLE I

Sample protocol of test for basal secretion in a normal young man

\begin{tabular}{c|c|c|c|c}
\hline \hline $\begin{array}{c}\text { Number of } \\
\text { specimen } \\
\text { (10- } \\
\text { minute } \\
\text { period) }\end{array}$ & Character of gastric juice & $\begin{array}{c}\text { Volume } \\
\text { per } \\
10- \\
\text { minute } \\
\text { period }\end{array}$ & $\begin{array}{c}\text { Free } \\
\text { acid }\end{array}$ & $\begin{array}{c}\text { Total } \\
\text { acid }\end{array}$ \\
\hline Fasting & $\begin{array}{l}\text { Moderately bile stained } \\
\text { mucoid material }\end{array}$ & 30 & 5 & 20 \\
1 & $\begin{array}{l}\text { Thin tinted fluid, moder- } \\
\text { ate amount of mucus }\end{array}$ & 13 & 62 & 72 \\
2 & $\begin{array}{l}\text { Same } \\
\text { Thin, clear, colorless; few } \\
\text { particles of mucus }\end{array}$ & 14 & 73 & 82 \\
4 & $\begin{array}{l}\text { Same } \\
5\end{array}$ & 15 & 73 & 82 \\
Same & 14 & 74 & 85 \\
\hline
\end{tabular}

\section{Basal secretion in peptic ulcer}

The highly acid profuse secretion of patients with peptic ulcer has been repeatedly described, but the observations have usually been made after either a test meal or an injection of histamine (2). We have found no record of studies of basal secretion in peptic ulcer although it seems highly important to know about the "spontaneous" activities of the secreting cells in this disease.

Studies of basal secretion were made in twenty instances of peptic ulcer ( 11 duodenal, 9 gastric). The diagnosis was proved in each case by $x$-ray, operation, or gastroscopy. For the purposes of 
this study (see below) we selected from a larger series cases in whom healing of the ulcer was very rapid (10 days to 3 weeks) or in whom the ulcer was quite refractory to therapy.

\section{RESULTS}

In Table II are shown the acidity and volume of the basal secretion in these cases. There are

TABLE II

Summary of findings in 20 cases of peptic ulcer

\begin{tabular}{|c|c|c|c|c|c|c|c|c|c|c|}
\hline \multicolumn{6}{|c|}{ Gastrio } & \multicolumn{5}{|c|}{ Duodenal } \\
\hline \multirow{2}{*}{ Name } & \multirow{2}{*}{ Age } & \multirow{2}{*}{ Bex } & \multirow{2}{*}{ Sire of ulcer } & \multicolumn{2}{|c|}{$\underset{\text { Becretion }}{\text { Bassl }}$} & \multirow{2}{*}{ Name } & \multirow{2}{*}{ Sex } & \multirow{2}{*}{ Age } & \multicolumn{2}{|c|}{$\underset{\text { secretlon }}{\text { Bassl }}$} \\
\hline & & & & \begin{tabular}{|l|} 
Vol- \\
ume
\end{tabular} & Aoldity & & & & $\begin{array}{l}\text { Vol- } \\
\text { ume }\end{array}$ & $\begin{array}{c}\text { Aold- } \\
\text { ity }\end{array}$ \\
\hline $\begin{array}{l}\text { Tu. } \\
\mathbf{L} . \\
\text { Ma. } \\
\text { Lu. } \\
\text { Le. } \\
\text { Ko. } \\
\text { Ch. } \\
\text { Ku. }\end{array}$ & $\begin{array}{c}\text { years } \\
\mathbf{4 5} \\
\mathbf{5 1} \\
\mathbf{4 7} \\
\mathbf{5 1} \\
\mathbf{3 3} \\
\mathbf{3 5} \\
\mathbf{5 8} \\
\mathbf{5 6}\end{array}$ & $\begin{array}{l}\mathbf{F} \\
\mathbf{M} \\
\mathbf{M} \\
\mathbf{M} \\
\mathbf{M} \\
\mathbf{F} \\
\mathbf{M} \\
\mathbf{M}\end{array}$ & $\begin{array}{l}\text { "Small" } \\
1 \mathrm{~cm} . \\
2.5 \times 4.0 \mathrm{~cm} . \\
2.5 \times 2.0 \mathrm{~cm} . \\
1.5 \mathrm{~cm} . \\
2 \mathrm{~cm} . \\
\text { "Large" } \\
1 \mathrm{~cm} .\end{array}$ & $\begin{array}{r}\propto . \\
9 \\
20 \\
13 \\
4 \\
5 \\
14 \\
19 \\
5\end{array}$ & $\begin{array}{l}77 \\
66 \\
45 \\
44 \\
38 \\
0(\text { free) } \\
0 \text { (free) } \\
\text { O(free) }\end{array}$ & $\begin{array}{l}\text { WL. } \\
\text { Re. } \\
\text { To. } \\
\text { Ca. } \\
\text { Ba. } \\
\text { Ban. } \\
\text { Sh. } \\
\text { Ro. } \\
\text { Ra. } \\
\text { Gr. } \\
\text { Ha. }\end{array}$ & $\begin{array}{l}\mathbf{M} \\
\mathbf{M} \\
\mathbf{M} \\
\mathbf{M} \\
\mathbf{M} \\
\mathbf{M} \\
\mathbf{M} \\
\mathbf{M} \\
\mathbf{M} \\
\mathbf{M} \\
\mathbf{F}\end{array}$ & $\begin{array}{c}\text { years } \\
46 \\
35 \\
27 \\
20 \\
38 \\
39 \\
33 \\
52 \\
46 \\
42 \\
49\end{array}$ & $\begin{array}{r}c . \\
16 \\
30 \\
13 \\
9 \\
11 \\
13 \\
13 \\
13 \\
8 \\
10 \\
6\end{array}$ & $\begin{array}{r}140 \\
136 \\
126 \\
126 \\
120 \\
98 \\
80 \\
75 \\
72 \\
54 \\
24\end{array}$ \\
\hline
\end{tabular}

* "Volume" of secretion is the output obtained during a ten-minute period at the basal level. "Acidity" is total acidity as titrated in the usual way.

several points of note. First there is a marked difference in the rate of secretion and acidity of various cases, in contrast to the uniformly high values after histamine. One-third of the cases of gastric ulcer had no free acid, one-half of the cases with duodenal ulcer poured out juice with an acidity as high as 120 to 140 even under basal conditions. Decline of gastric acidity with advancing years has been pointed out by Polland (2); but his data were obtained by means of histamine tests or Ewald meals. Relation of acidity to age is brought out very clearly in this series and is even more notable with juice secreted under basal conditions than with histamine juice. The average acidity, for example, of five patients with duodenal ulcer with an average age of 47 years was 73 ; the acidity of five with an average age of 30 was 117.6. Four patients with gastric ulcer with an average age of 54 had acidity of 27.5 , five with an average age of 38 had acidity of 52.5 . In this small series there was no definite relation of volume of secretion to age among the cases with gastric ulcer, but such a relation is clearly seen in those with duodenal ulcer, the average volume in the five youngest patients being $15.2 \mathrm{cc}$. and in the five oldest $10.6 \mathrm{cc}$.

Of special interest seemed the great difference in acidity of the gastric and duodenal cases. With histamine tests the average acidity of duodenal cases is slightly higher than that of the gastric, but there is no such discrepancy as appears when the basal juice is tested. In this series, the average age of 9 patients with gastric ulcer was 47 years with average gastric acidity of 40.5 ; the average of 11 cases with duodenal ulcer was 39 with average acidity of 95.5 , more than double that of the gastric cases. The difference in age of 8 years of the two groups certainly could not account for the discrepancy, and these findings reinforce the feeling we have had for some time that gastric and duodenal ulcer are essentially different disorders.

\section{Relation of gastric acidity to healing of peptic ulcer}

Reduction of gastric acidity is, in the minds of most physicians, the main objective in the therapy of peptic ulcer, and certainly it is hard to believe that healing of an eroded surface can proceed readily in a medium bathed in corrosive fluid. But the situation is much more complex. It is common knowledge, for example, that the bowel ulcers of typhoid disappear with amazing speed, when the infection has spent its force, even under a fecal current alive with bacteria. So, too, everyone has seen deep peptic ulcers heal within two or three weeks despite an extremely high gastric acidity. It may well be that the mucosa of the stomach is adapted to its acid bath in contrast to the jejunum which becomes eroded so readily if acid stomach contents are diverted into it by means of gastro-enterostomy. Brown and Dolkart (3) have recently reviewed the subject and find no correlation between the course of peptic ulcer and gastric acidity; unfortunately, they used the Ewald test meal with which there is ordinarily so much variation that no conclusions can be drawn.

It seemed of interest to investigate the subject from the standpoint of basal gastric secretion to 
see whether any correlation exists between the course of peptic ulcer and the character of the spontaneous gastric secretion without complicating the situation by the use of any test meal or secretory stimulus.

For purposes of analysis the groups of duodenal and peptic ulcer were further subdivided into those which healed promptly and those which were refractory to medical treatment consisting of rest -more or less complete-a simple dietary regimen, and belladonna. No systematic alkalinization was practiced. Drugs were of course omitted before the basal juice was collected. The results are best shown graphically (Figure 1). While

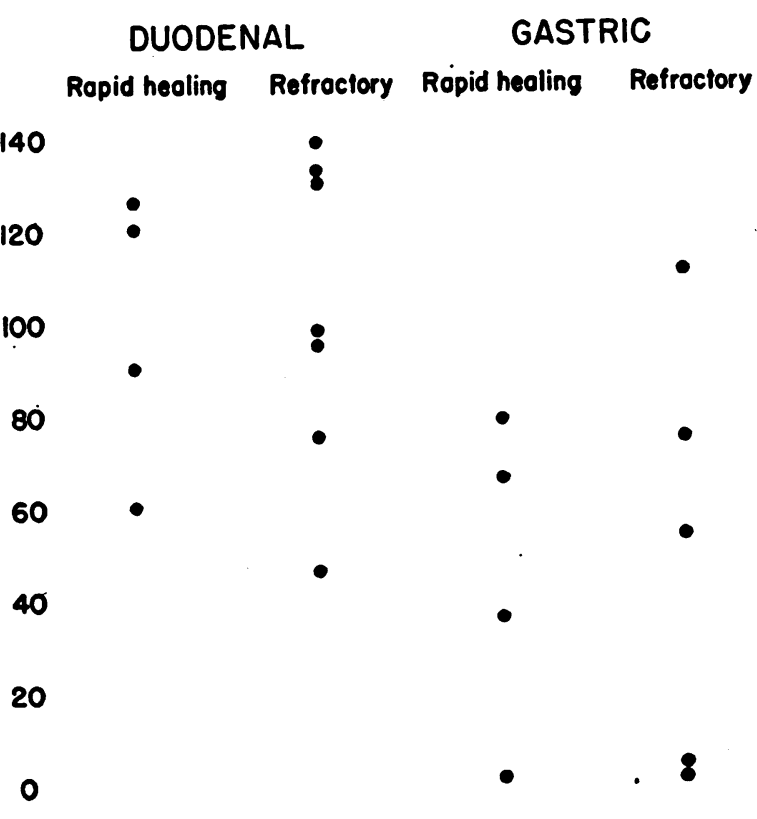

Fig. 1. Relation of Healing of Peptic Ulcer to Basal Actdity

Each dot indicates the acidity in a single case.

the number of cases is too small for mathematical analysis, it is quite clear that in this series there is no relation between basal acidity and speed of healing. In other words, ulcer may heal rapidly with high or low acid or may be refractory with high or low acid. As a matter of fact, the average acidity of the cases with duodenal ulcer with rapid healing was 95 , the acidity of those which were refractory 96 ; with the ulcers of the stomach the corresponding figures were 37 and 48 .
In conclusion, we present two illustrative cases.

Case 1. Rapid healing of ulcer despite high basal secretion. M. B., a man aged 38, had had indigestion for about 8 years. For the past three weeks the symptoms were constant and severe and he had passed black stools. Physical examination was not remarkable. Hemoglobin 78 per cent (12 grams per cent). X-rays (March 9, 1937) showed marked six-hour retention and great deformity of the duodenal bulb. There was rapid improvement of symptoms under usual therapy. X-rays (March $17,1937)$ showed no retention, bulb filled and was regular. On June 4, 1937, the patient was reported as being well. Test done on March 22, 1937, showed a basal acidity of 120.

Case 2. Ulcer refractory to healing in spite of basal anacidity. S. G., a 58-year old man, was seen in November 1936 for epigastric distress, 6 years in duration. He had passed black stools, and the hemoglobin was 48 per cent. X-ray (November 6, 1936) showed a large gastric ulcer on the lesser curvature. February 13, 1937, in spite of treatment, $\mathbf{x}$-ray showed crater unchanged. Resection revealed a benign ulcer. Test done February 16,1937 , at which time his hemoglobin was 75 per cent, yielded no free acid but large amounts of clear glairy mucus with the appearance and consistency of egg white. In spite of what one might expect to be a favorable medium for healing, the ulcer was highly refractory to treatment.

\section{COM MENTS}

Attention is called again to the value of studies of basal gastric secretion as a supplement to the conventional test-meal methods. The findings in cases of duodenal ulcer are of special interest since these patients for the most part pour out a continuous highly acid secretion, the average basal acidity in this group being 95.5, a value as high as that obtained in many normal controls even after histamine stimulation. The average basal acidity of the cases with gastric ulcer, on the other hand, was much lower (40.5). Conventional views as to the relationship of acidity to the formation of ulcer and to healing are unfortunately not clarified by these observations which reveal no correlation between speed of healing and degree of acidity. They seem to indicate that acidity is certainly not the major determining factor.

\section{SUMMARY}

1. Studies of basal secretion in cases of peptic ulcer show that the average basal acidity in duo- 
denal ulcer was approximately twice as high as in gastric ulcer.

2. Basal acidity in individual cases of peptic ulcer varied from 0 to 95 ; in duodenal ulcer from 24 to 140 .

3. There was no correlation between the degree of acidity and the speed of healing of either duodenal or gastric ulcer.

\section{BIBLIOGRAPHY}

1. Polland, W. S., and Bloomfield, A. L., Basal gastric secretion in man. Bull. Johns Hopkins Hosp., 1931, 49, 302.

2. Polland, W. S., Histamine test meals. An analysis of 988 consecutive cases. Arch. Int. Med., 1933, 51, 903.

3. Brown, C. F. G., and Dolkart, R. E., Gastric acid during recurrences and remissions of duodenal ulcer. Arch. Int. Med., 1937, 60, 680. 